JIIF (Jurnal Ilmu dan Inovasi Fisika)

Vol. 02, No. 02 (2018) 137 - 144

(C) DepartemenFisika FMIPA UniversitasPadjadjaran

\title{
PENENTUAN DAERAH RAWAN BENCANA SAMBARAN PETIR DI WILAYAH KABUPATEN DAN KOTA BANDUNG JAWA BARAT
}

\author{
ERWAN SUSANTO \\ Badan Meteorologi Klimatologi dan Geofisika, \\ Stasiun Geofisika Kelas II Gowa \\ Jl. Malino Km 2, Tamarunang, Somba Opu,Gowa92101 \\ *email : erwan.susanto@gmail.com
}

\begin{abstract}
Abstrak. Petir merupakan salah satu fenomena alam yang sangat berbahaya karena besarnya energi yang dikeluarkan setiap kali petir menyambar bisa mencapai jutaan volt. Besarnya energi tersebut dapat menghancurkan apa saja yang disambarnya. Kejadian petir, khususnya petir tipe $C G$ selalu bersinggungan dengan aktivitas manusia sehingga tidak jarang petir menyebabkan kerugian material atau bahkan menyebabkan kematian. Kabupaten dan Kota Bandung merupakan pusat pemerintahan dari Provinsi Jawa Barat dengan jumlah penduduk yang sangat padat sehingga harus mengantisipasi bencana yang mungkin terjadi untuk meminimalisir kerugian yang ditimbulkan. Penelitian ini menggunakan data petir tipe CG (Cloud to Ground) tahun 2017 hasil rekaman sensor Lightning Detector BMKG Stasiun Geofisika Kelas I Bandung. Penelitian ini bertujuan untuk mengetahui daerah yang rawan terhadap bencana sambaran petir di Kabupaten dan Kota Bandung. Hasil penelitian ini diharapkan mampu menjadi informasi bagi pemerintah dan masyarakat khususnya di wilayah Kabupaten dan Kota Bandung untuk mengantisipasi bencana sambaran petir. Penelitian ini menggunakan metode analisis spasial dengan metode classtering. Hasil dari penelitian ini menunjukkan bahwa ada 4 kecamatan yang rawan bencanaa sambaran petir yaitu Kecamataan Lembang, Cisarua, Cipeundeuy dan Cikalong Wetan.
\end{abstract}

Kata kunci : Petir Tipe CG, Lightning Detector, Daerah Rawan

\begin{abstract}
Lightning is one natural phenomenon that is very dangerous because the amount of energy released every time lightning strike can reach millions of volts. The amount of energy can destroy anything that struck. Lightning events, especially lightning type CG always tangent to human activity so that not infrequently lightning causes material loss or even cause death. Regency and City Bandung is the center of government from West Java Province with a very dense population so that should anticipate the disaster that may occur to minimize the losses incurred. This research uses lightning data type CG (Cloud to Ground) in 2017 results of sensorlightning detector BMKG Class I Geophysical Station Bandung. This study aims to determine the areas that are prone to lightning strikes in the district and the city of Bandung. The results of this study is expected to be information for the government and society, especially in the area of Bandung Regency and City to anticipate the lightning strike disaster. This research uses spatial analysis method with classtering method. The results of this study indicate that there are 4 sub-districts that are vulnerable to lightning strikes namely LembangSub-districts, Cisarua, Cipeundeuy and CikalongWetan.
\end{abstract}

Keywords :Lightning Type CG, Lightning Detector, ProneAreas 


\section{Pendahuluan}

Petir merupakan salah satu fenomena alam yang sangat berbahaya karena besarnya energi yang dikeluarkan setiap kali petir menyambar bisa mencapai jutaan volt. Besarnya energy tersebut dapat menghancurkan apa saja yang disambarnya. Kejadian petir, khususnya petir tipe $C G$ selalu bersinggungan dengan aktivitas manusia sehingga tidak jarang petir menyebabkan kerugian material atau bahkan menyebabkan kematian.

Kabupaten dan Kota Bandung merupakanpusat pemerintahan dariProvinsiJawa Barat yang merupakan salah satu kota besar di Pulau Jawa.Hal tersebut menjadikan daerah tersebut maju secara ekonomi dan menjadi salah satu tujuan bagi pencari kerja ataupun wisatawan. Kabupaten dan Kota Bandung memiliki jumlah penduduk yang cukup padat. Kabupaten dan Kota Bandung terdiri dari 67 kecamatan, berdasarkan data dari BPS tahun 2017 Kabupaten bandung mempunyai jumlah penduduk 3.596.623 jiwa, sedangkan Kota Bandung mencapai 2.481.469 jiwa.

Rumusan masalah yang ingin dipecahkan dalam penelitian ini adalah daerah mana yang rawan terhadap bencana sambaran petir?

Tujuan dari penelitian ini adalah untuk mengetahui daerah yang rawan bencana sambaran petir di wilayah Kabupaten dan Kota Bandung Jawa Barat.

Hasil dari penelitian ini diharapkan mampu menjadi sumber informasi bagi pemerintah maupun masyarakat di daerah rawan bencana sambaran petir untuk mengantisipasi jika petir terjadi. Sehingga dapat meminimalisir kerugian yang ditimbulkan akibat sambaran petir.

Petir. Petir adalah salah satu peristiwa alam, berupa pelepasan muatan listrik dengan arus yang cukup tinggi dan bersifat transient (singkat) yang terjadi diatmosfer. Penyebabnya adalah berkumpulnya ion bebas bermuatan positif $(+)$ dan negative (-) diatmosfer khususnya diawan Cumulonimbus $(C B)$. Ion listrik tersebut dihasilkan oleh gesekan antara partikel uap air diawan dan juga kejadian ionosasi ini disebabkan oleh peru bahan bentuk air mulai dari cair menjadi gas atau sebaliknya, bahkan padat(es) menjadi cair. Petir terjadi diakibatkan karena adanya perbedaan potensial antara dua medium yang mengakibatkan terjadinya perpindahan muatan untuk mencapai kesetimbangan. Besarnya energy dari pelepasan muatan tersebut menimbulkan terjadinya Guntur atau halilintar yaitu rentetan cahaya, panas dan bunyi yang sangat kuat. Ketika akumulasi muatan listrik dalam awan tersebut telah membesar dan stabil, maka lompatan listrik yang terjaditersebutakanmerambahkemassabermedanlistriklainnya. Perbedaan tegangan litriksaat terjadi petir adalah melebihi beberapa jutavolt, seperti dalam [5].

Petir didalam awan (Intra Cloud/ IC). Petir jenis ini adalah petir yang paling sering terjadi. Petir jenis ini disebabkan karena adanya pusat-pusat muatan yang berbeda dalam satu awan, seperti dalam [5]. 


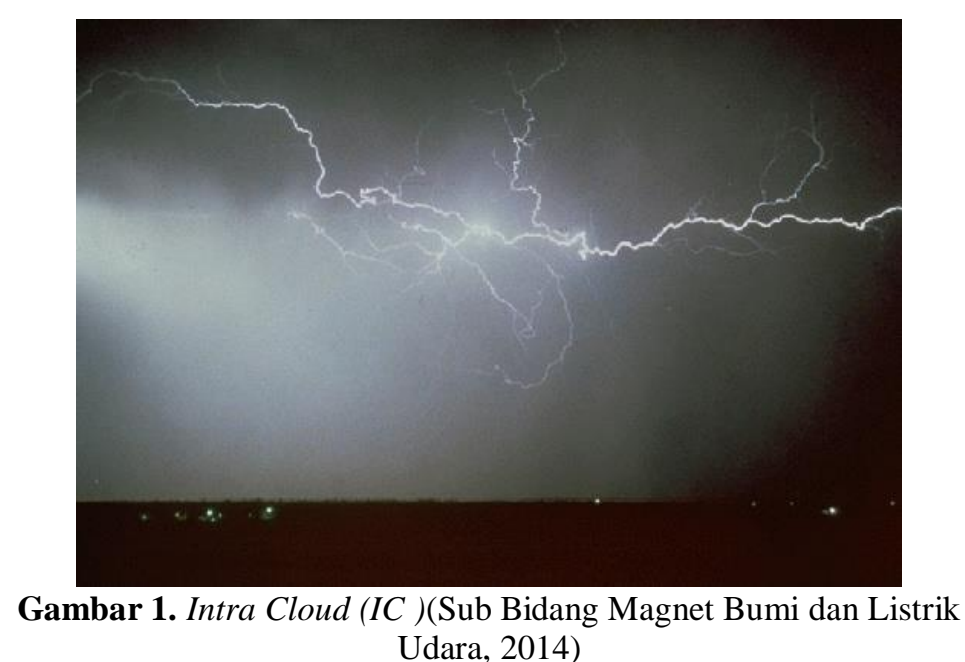

Udara, 2014)

Petir dari awan ke awan (Cloud to Cloud /CC). Petir jenis ini terjadi karena adanya dua muatan yang berbeda pada awan yang berbeda, seperti dalam [5].

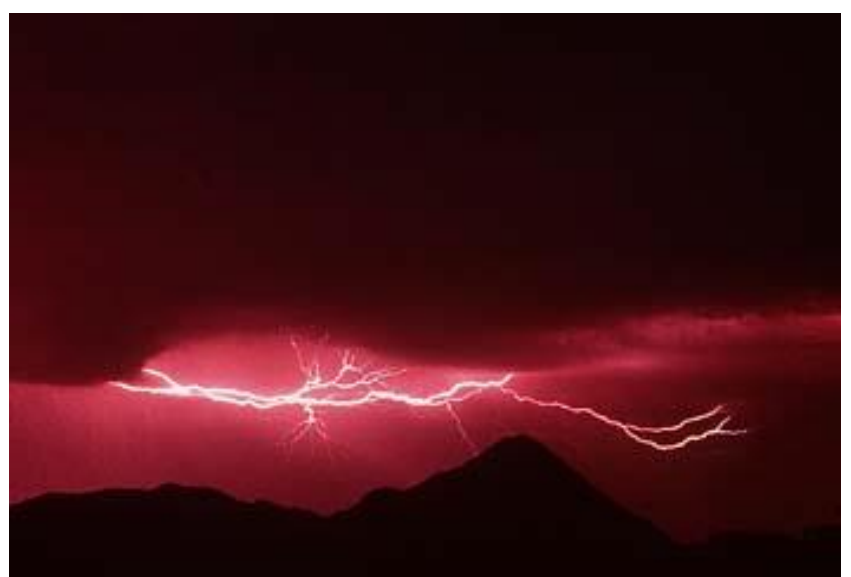

Gambar 2. Cloud to Cloud (CC) (Sub Bidang Magnet BumidanListrikUdara, 2014)

Petir awan ke udara (Cloud to Air / CA). Petir jenis ini terjadi akibat udara disekita rawan positif (+) berinteraksi dengan udara yang bermuatan negatif (-), seperti dalam [5]. 


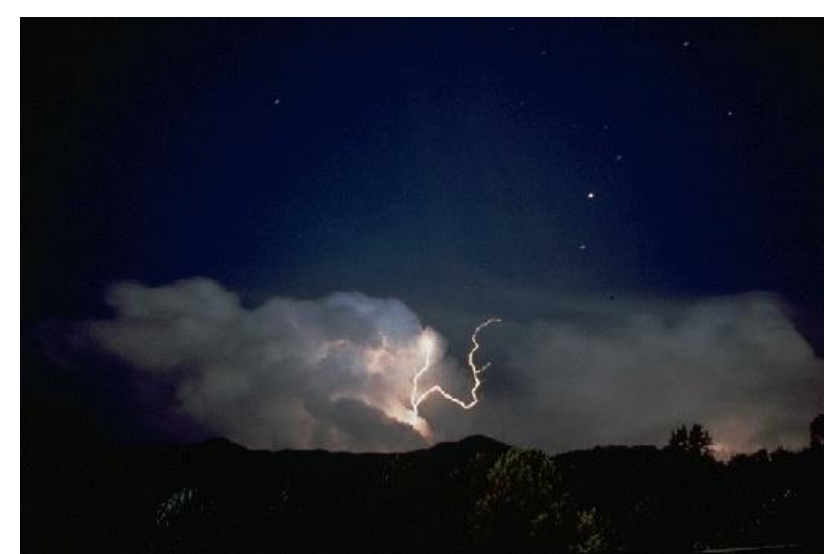

Gambar3.Cloud to Air(CA)(Sub Bidang Magnet BumidanListrikUdara, 2014)

Petir dari awan ke tanah(Cloud to Ground/CG). Petir jenis ini adalah yang paling berbahaya dan merusak karena petir jenis $C G$ adalah jenis petir yang langsung bersinggungan dengan aktifitas manusia, seperti dalam [5].

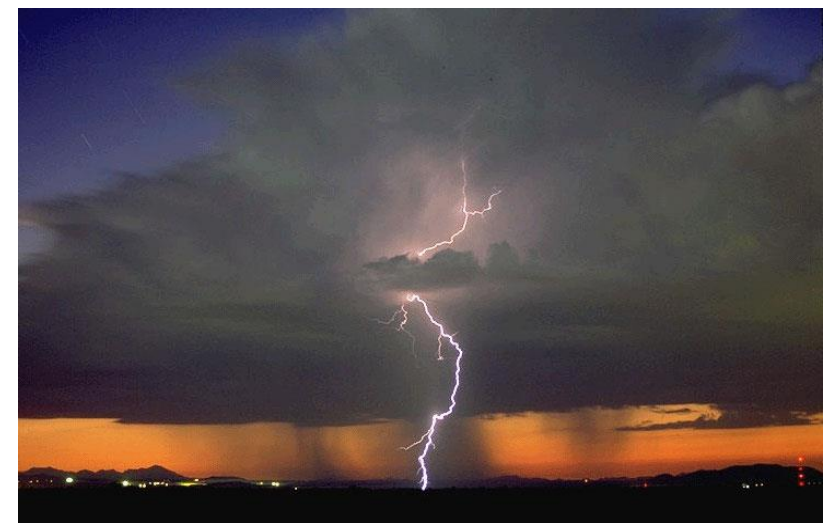

Gambar4. Cloud to Ground (CG) (Sub Bidang Magnet BumidanListrikUdara, 2014)

Petir $\boldsymbol{C} \boldsymbol{G}$ negative (-). Pada petir jenis ini terjadi sambaran berulang-ulang dan bercabang-cabang. Petir tipe ini terjadi akibat induksi medan listrik positif (+) di permukaan bumi dengan bagian pusat awan yang bermuatan negatif (-), seperti dalam [5].

Petir $\boldsymbol{C} \boldsymbol{G}$ positif (+). Pada petir jenis ini hanya terjadi satu kali sambaran. Petir jenis ini terjadi akibat induksi medan listrik negatif (-) di permukaan bumi dengan bagian atas awan yang terkonsentrasi muatan listrik positif (+), seperti dalam [5].

\section{Metode Penelitian}

Data yang digunakan dalam penelitian ini adalah petir tipe $C G$ selama tahun 2017 yang tercatat pada alat Lightning Detector Stasiun Geofisika Kelas 1 Bandung, data data luas wilayah per kecamatan di Kabupaten dan Kota Bandung dari Badan Informasi Geospasial (BIG). 
Penelitian ini menggunakan metode yang sebelumnya pernah digunakan pada [10], yaitu metode analisis spasial dengan metode classtering. Metode analisis spasial adalah metode analisis yang berhubungan dengan ruang, yaitu kecamatan di wilayah Kabupaten dan Kota Bandung. Metode classtering adalah metode yang digunakan untuk menggelompokkan data petir berdasarkan kecamatan di wilayah Kabupaten dan Kota Bandung.

Pada Gambar 6. dapat terlihat bahwa ada beberapa langkah - langkah untuk menentukan daerah rawan bencana sambaran petir yaitu :

1. Data petir awal format *.ldc dirubah menjadi format *.kml dengan software Lightning/2000.

2. Data lintang dan bujur dalam format *.kml masih menyatu. Untuk memisahkannya dirubah kedalam format *.csv menggunakan software KML to CSV Converter 2.0.

3. Data dengan format *.csv dirubah menjadi format *.xls menggunakan software Lightning Data Prosessing.

4. Hitung nilai kerapatan sambaran petir dengan membandingkan dengan luas wilayah kecamatan menggunakan rumus sebagai berikut :

$d=\frac{\bar{X}}{A_{W i l}}$

Keterangan :

$d$ : kerapatan sambaran petir per kecamatan

$\bar{X} \quad$ : jumlahsambaranpetir per kecamatan

$A_{W i l}$ : luas wilayah kecamatan $\left(\mathrm{km}^{2}\right)$

5. Membagi kerapatan sambaran petir menjadi 3 tingkatan yaitu tingkat rendah, sedang dan tinggi dengan persamaan :

$I_{\text {Ancaman }}=\frac{\Delta d}{3}$.

Keterangan :

$I_{\text {Ancaman }}$ : interval tiap tingkat ancaman sambaran petir

$\Delta d$ : rentang nilai kerapatan sambaranpetir per $\mathrm{km}^{2}$ 


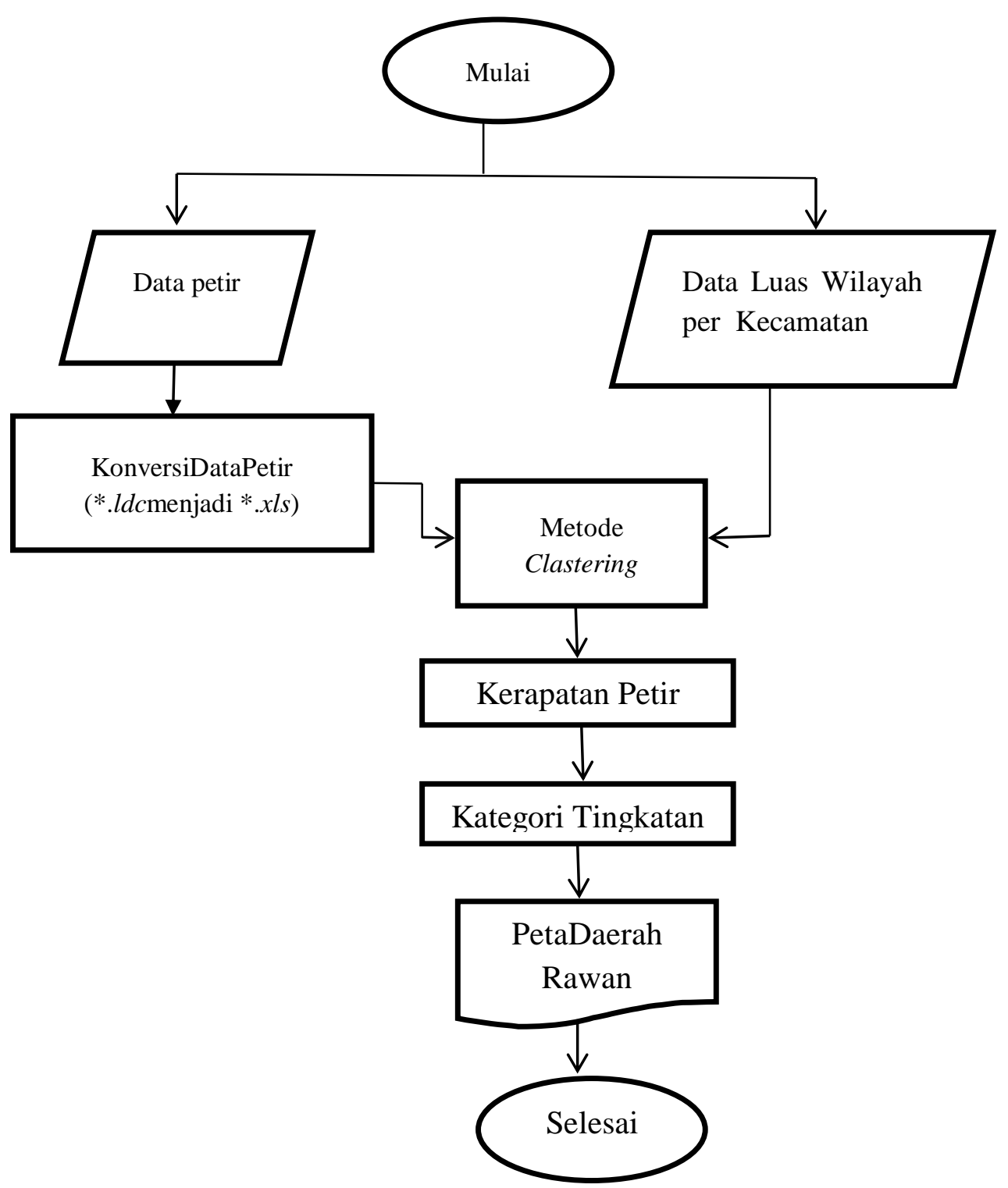

Gambar 5. Diagram Alir pengolahan Data

\section{Hasil dan Pembahasan}

Penentuan daerah rawan bencana sambaran petir di wilayah Kabupaten dan Kota Bandung sangat tergantung dengan frekuensi petir yang terjadi dan luas wilayah. Kedua faktor tersebut adalah faktor utama dalam menentukan nilai kerapatan petir, karena semakin tinggi nilai kerapatan petirnya makan akan semakin rawan daerah tersebut. Kerapatan sambaran petir diperoleh dengan cara membagi jumlah sambaran dalam satu kecamatan dengan luas wilayahnya.Nilai kerapatan sambaran petir selanjutnya dibagi menjadi 3 tingkatan yaitu rendah dengan nilai kerapatan sambaran petir kurang dari 41 sambaran petir per $\mathrm{km}^{2}$, sedang dengan nilai kerapatan sambaran petir antara 41 sampai 82 sambaranper $\mathrm{km}^{2}$ dan 
tinggidengan nilai kerapatan sambaran lebih dari 82 sambaranper $\mathrm{km}^{2}$. Daerah yang dikatakan rawan adalah daerah yang mempunyai tingkat kerapatan sambaran petir tinggi. Daerah yang rawan terhadap bencana sambaran petir harus diwaspadai jika akan terjadi petir. Setelah dilakukan perhitungan dan dikategorikan tingkatannya selanjutnya dibuat kedalam peta.

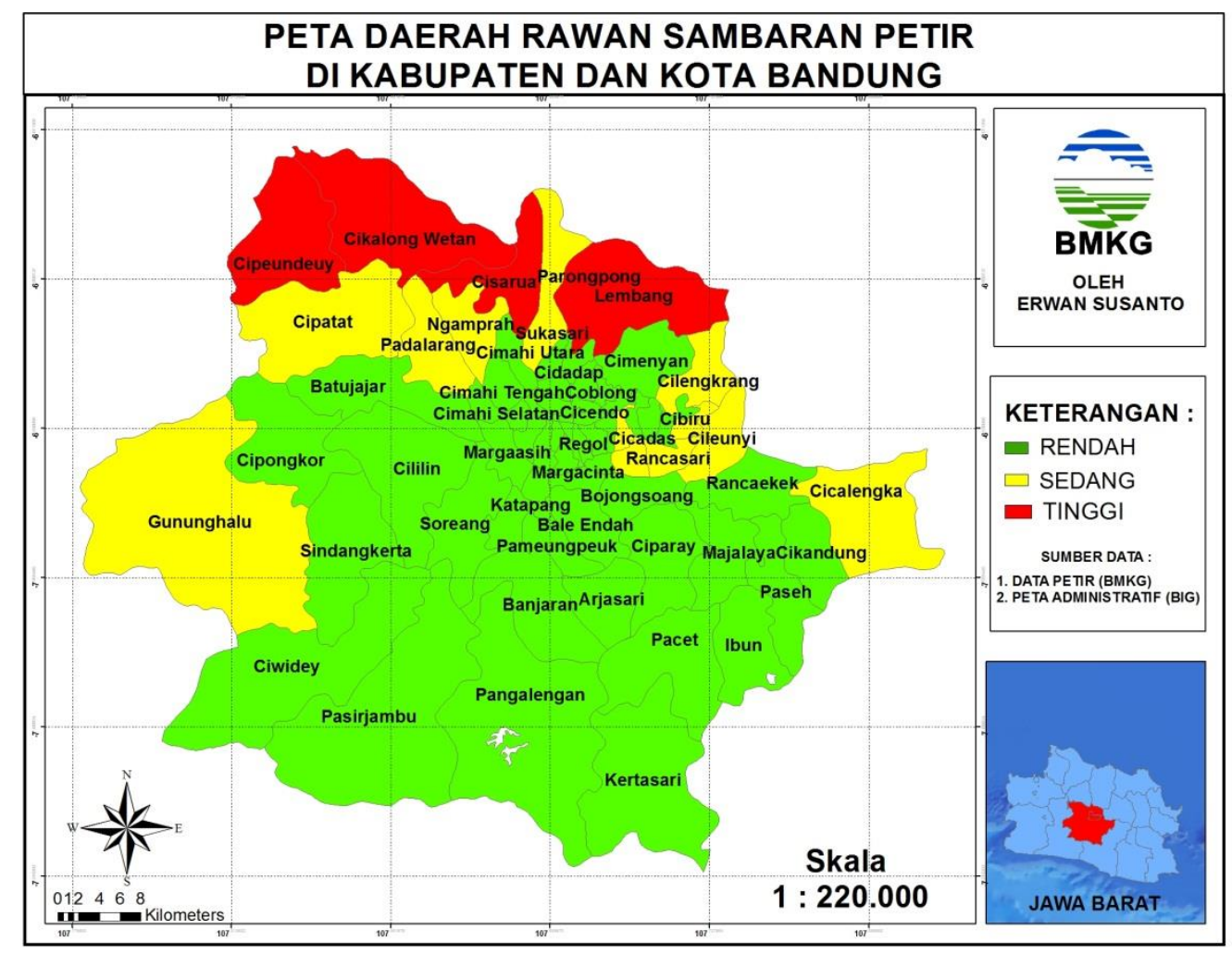

Gambar 6. Peta Daerah Rawan Sambaran Petir di Kabupaten dan Kota Bandung

Gambar 6.adalah peta daerah rawan sambaran petir di wilayah Kabupaten dan Kota Bandung. Hasil penelitian ini menunjukkan bahwa di wilayah Kabupaten dan Kota Bandung 51 kecamamatan memiliki kerapatan sambaran petir rendah, 12 kecamatan memiliki kerapatan sambaran petir sedang dan 4 kecamataan memiliki kerapatan sambaran petir tinggi. Kecamatan dengan kerapatan sambaran petir tinggi adalahKecamatan Lembang dengan kerapatan sambaran petir 109 sambaran perkm², Kecamatan Cisarua 154 sambaran perkm²,Kecamatan Cipeundeuy 187 sambaran perkm² danKecamatan Cikalong Wetan 249 sambaran perkm².Hal tersebut dapat diartikan bahwa 4 kecamatan di wilayah Kabupaten dan Kota Bandung rawan terhadap bencana sanbaran petir yaituKecamatan Lembang, Cisarua, Cipeundeuy dan Cikalong Wetan.

\section{Kesimpulan}

Kesimpulan dari penelitian ini adalah di wilayah Kabupaten dan Kota Bandung terdapat 4 kecamatan yang rawan terhadap bencana sambaran petir yaituKecamatan Lembang, Cisarua, Cipeundeuy dan Cikalong Wetan. Kecamatan dengan nilai kerapatan sambaran petir paling tinggi adalah Kecamatan Cikalong 
Wetan dengan 249 sambaran perkm². Daerah yang rawan terhadap bencana sambaran petir haru selalu waspada dan mengantisipasi jika terjadi petir.

\section{Ucapan terima kasih}

Ucapan terima kasih yang pertama penulis sampaikan kepada Allah SWT yang telah melimpahkan rahmat serta karunianya sehingga penulis dapat menyelesaikan penelitian ini. Ucapan terima kasih yang kedua penulis sampaikan kepada kedua Orang Tua yang selalu mendoakan dan memberikan dukungan baik material maupun moral. Ucapan terima kasih yang ketiga penulis sampaikan kepada instansi BMKG yang sudah membantu dalam ketersediaan data petir. Ucapan terima kasih juga penulis sampaikan kepada Kepala Stasiun, Kasie Obs, Kasubag. TU dan teman - teman di Stasiun Geofisika Kelas II Gowa.

\section{DaftarPustaka}

1. I. B. F. Arafat, Analisis Tingkat Kerawanan Bahaya Sambaran Petir Dengan Metode Simple Additive Weighting (SAW) di Wilayah Kabupaten dan Kota Bogor, Jurusan Geofisika, STMKG, Tangerang Selatan (2015).

2. BPS Kabupaten Bandung, Kabupaten Bandung dalam Angka, BPS Kabupaten Bandung, Bandung (2017).

3. BPS Kota Bandung, Kota Bandung dalam Angka, BPS Kota Bandung, Bandung (2017).

4. T. Gunawan, L. Naomi, L. Pandiangan, Analisis Tingkat Kerawanan Bahaya Sambaran Petir Dengan Metode Simple Additive Weightingdi ProvinsiBali, Jurnal, BBMKGWil.III,Denpasar (2014).

5. M. Husni, Magnet Bumidan Listrik Udara, STMKG, Tangerang Selatan (2012).

6. M. Husni, Perkembangan Pengamatan Petir BMKG, Seminar Ilmiah MKG Puslitbang BMKG, Jakarta, 19 Oktober 2016.

7. R. E. Radjah, Penentuan Tingkat Kerawanan Sambaran Petir di Wilayah Kabupaten Sumba Timur Menggunakan Metode Simple Additive Weighting (SAW), Jurusan Geofisika, STMKG, Tangerang Selatan (2016).

8. T. D. Riadi, T.D, Analisis Pemetaan Tingkat Resiko Bahaya Sambaran Petir Dengan Metode Simple Additive Weighting di Wilayah Kota Ambon, Kabupaten Maluku Tengah dan Kabupaten Seram Bagian Barat, Jurusan Geofisika, STMKG, Tangerang Selatan (2016).

9. Sub Bidang Magnet Bumi dan Listrik Udara, Monitoring Petir di Indonesia, Jakarta (2014).

10. E. Susanto, Analisis Korelasi Kepadatan Bangunan Terhadap Tingkat Kuat Arus Sambaran Petir di Wilayah Kota Makassar, Prosiding Pertemuan Ilmiah Mahasiswa Fisika Indonesia 2018, Jurusan Fisika FMIPA UNHAS, Makassar, GL-FU06

11. E. Susanto, E, Analisis Spasial dan Temporal Kejadian Petir CG di Wilayah Kabupaten Gowa, Sulawesi Selatan, Jurusan Geofisika, STMKG, Tangerang Selatan (2017).

12. M.A. Uman, M.A, Lightning, Dover PublicationInc.,New York (2001). 